\title{
Test Program for Stirling Radioisotope Generator Hardware at NASA Glenn Research Center
}

\author{
Edward J. Lewandowski ${ }^{1}$ \\ NASA Glenn Research Center, Cleveland, OH 44135 \\ Gary S. Bolotin ${ }^{2}$ \\ Jet Propulsion Laboratory, California Institute of Technology, Pasadena, CA 91109 \\ and \\ Salvatore M. Oriti ${ }^{3}$ \\ NASA Glenn Research Center, Cleveland, OH 44135
}

\begin{abstract}
Stirling-based energy conversion technology has demonstrated the potential of high efficiency and low mass power systems for future space missions. This capability is beneficial, if not essential, to making certain deep space missions possible. Significant progress was made developing the Advanced Stirling Radioisotope Generator (ASRG), a 140-watt radioisotope power system. A variety of flight-like hardware, including Stirling convertors, controllers, and housings, was designed and built under the ASRG flight development project. To support future Stirling-based power system development NASA has proposals that, if funded, will allow this hardware to go on test at the NASA Glenn Research Center (GRC). While future flight hardware may not be identical to the hardware developed under the ASRG flight development project, many components will likely be similar, and system architectures may have heritage to ASRG. Thus the importance of testing the ASRG hardware to the development of future Stirling-based power systems cannot be understated. This proposed testing will include performance testing, extended operation to establish an extensive reliability database, and characterization testing to quantify subsystem and system performance and better understand system interfaces. This paper details this proposed test program for Stirling radioisotope generator hardware at NASA GRC. It explains the rationale behind the proposed tests and how these tests will meet the stated objectives.
\end{abstract}

\section{Introduction}

TIRLING-BASED energy conversion technology has demonstrated the potential of high efficiency and low $\checkmark$ mass power systems for future space missions. This capability is beneficial, if not essential, to making certain deep space missions possible. Significant progress was made developing the Advanced Stirling Radioisotope Generator (ASRG), a 140-watt radioisotope power system. A variety of flight-like hardware, including Stirling convertors, controllers, and housings, was designed and built under the ASRG flight development project, but saw only limited testing, and then only at the component and subsystem level. Under proposed funding, this hardware will go on test at the NASA Glenn Research Center (GRC) to support future Stirling-based power system development. While future flight hardware may not be identical to the hardware developed under the ASRG flight development project, many components will likely be similar, and system architectures may have heritage to ASRG. We are proposing to continue the testing the ASRG hardware to support the development of future Stirling-based power systems. This testing will include performance testing, extended operation to establish an extensive reliability database, and characterization testing to quantify subsystem and system performance and better understand system interfaces. This paper details the proposed test program for Stirling radioisotope generator hardware that is already

\footnotetext{
${ }^{1}$ Project Lead Engineer, Thermal Energy Conversion Branch, 21000 Brookpark Rd., AIAA Senior Member.

${ }^{2}$ System Engineer V, Power \& Space System, 4800 Oak Grove Drive.

${ }^{3}$ Mechanical Engineer, Thermal Energy Conversion Branch, 21000 Brookpark Rd.
} 
underway at NASA GRC. It explains the rationale behind the tests being conducted and how these tests will further advance the technology to meet the below stated objectives.

Figure 1 shows a diagram of the ASRG, as designed for flight by Lockheed Martin, the system integrator under contract to the Department of Energy. The ASRG contains two Advanced Stirling Convertors (ASCs) secured together with an interconnect tube. A General Purpose Heat Source (GPHS) module, held against each ASC heat collector, provides the heat input. The cold-side adapter flanges (CSAFs) conduct heat rejected from the convertors through the beryllium housing and fins, for radiation in a vacuum environment or convection to air. During ground operations argon fills the housing, sealed using o-rings and gaskets. A gas management valve allows access to the argon. A pressure relief device is provided to vent the argon during launch as the surrounding air pressure approaches the vacuum of space, improving effectiveness of the insulation surrounding the heat source. The controller is remotely mounted in a location determined by the mission and connected electrically to the generator housing assembly (GHA) via cables. Connectors on the housing and controller provide electrical interfaces to the alternators, sensors, power input and output, control, and telemetry. The GHA is secured to a spacecraft interface or support via four mounting tabs on one end of the GHA.

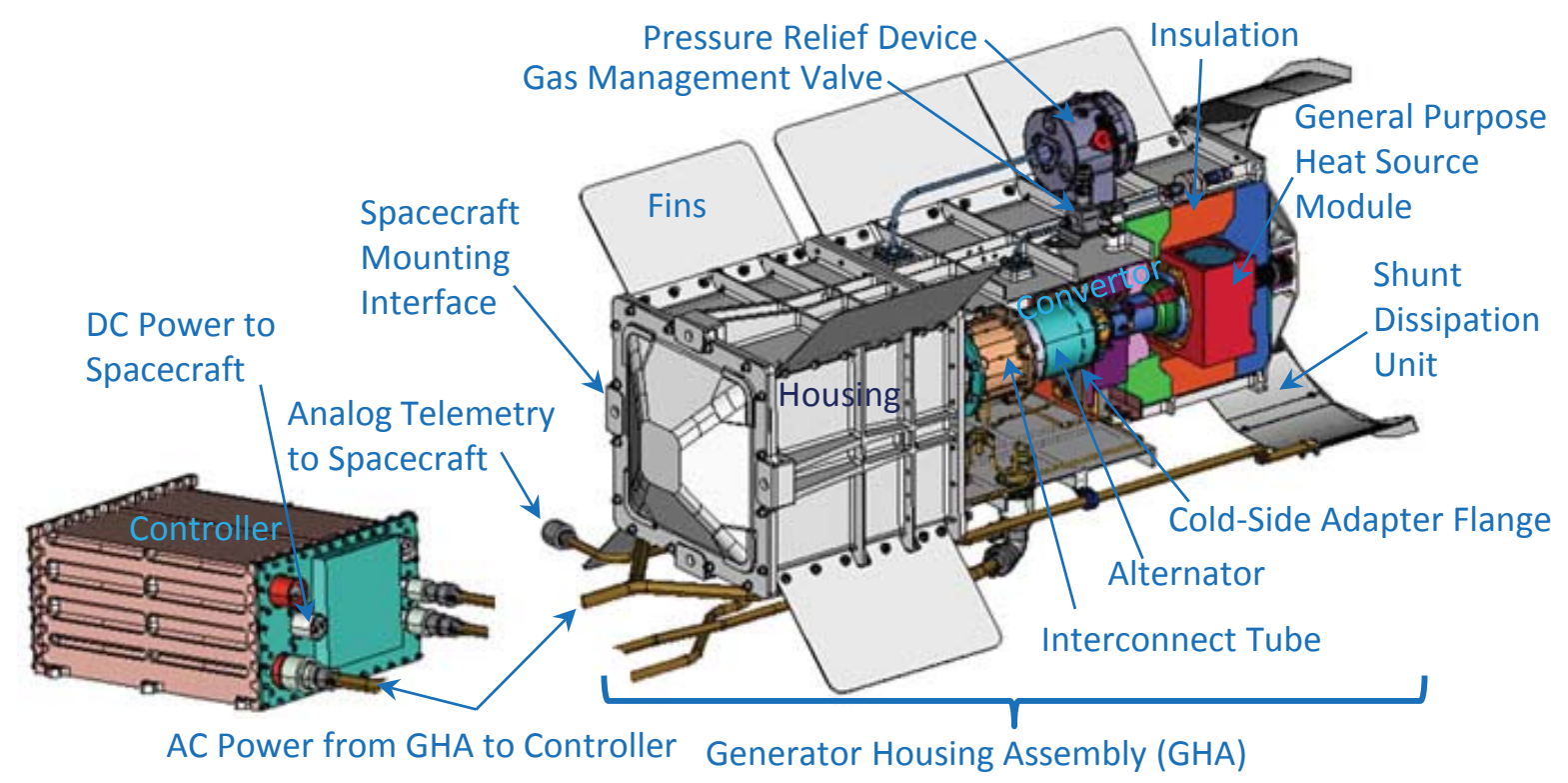

Figure 1. Diagram of the ASRG.

\section{Test Objectives}

The ASRG flight development project was terminated in late 2013, before assembly and test of the ASRG Qualification Unit (QU) had begun. While extensive analysis, modeling, and simulation had been completed at that point, a test of the as-built and integrated hardware had not been completed. Without this testing, the accuracy of system analysis and simulation cannot be confirmed, models cannot be validated, secondary effects and interactions would not be observed, and proof of many concepts of the ASRG, a complex dynamic power system with an active controller, would remain unproven and undemonstrated.

Some subsequent testing has been completed by Lockheed Martin of an ASC Controller Unit (ACU) controller, a pair of ASC-E3 convertors, and the flight electrical ground support equipment. ${ }^{1}$ This test provided insight and quantification of some ASC-ACU system level behavior, although results are limited because the ASCs were not in a flight-like environment in a GHA, and tests were not run to steady-state as the system was not operated 24/7 but was started up and shut down on a daily basis.

NASA GRC has contracted with Lockheed Martin (LM) to complete two engineering level ACUs (Engineering Development Unit (EDU) 4.0 and 4.1) based on the flight ACU design. These ACUs will be delivered to GRC in late 2014.

NASA has proposed plans to continue the advancement of Stirling-based power system technology for deep space missions and for human exploration. Stirling-based thermal to electrical power conversion is being considered 
for higher power radioisotope applications (approximately $350 \mathrm{~W}$ to $1 \mathrm{~kW}$ ) and for fission-based power systems 1 $\mathrm{kW}$ and above. While these power systems would likely have differences with ASRG, it is very likely that components will be similar. It's possible that a higher power radioisotope power system could be comprised of several ASCs. NASA is currently developing a $12 \mathrm{~kW}$ free-piston Stirling convertor for fission applications that bear similarities to the ASC design.

During the development of the ASRG system architecture, many complex interactions and behaviors were analyzed. A future Stirling power system's architecture may benefit from ASRG heritage by either adopting a similar architecture or improving on lessons learned from the ASRG experience. The system level nuances uncovered during ASRG development, analysis, and testing can inform future Stirling-based power systems.

Invariably, almost every test of a system integrated for the first time uncovers some new findings. A thorough and rigorous test of the flight-like ASRG system presents an opportunity to uncover findings, quantify behavior, and validate system models.

It must also be noted that while demonstrating an integrated power system can be technically straightforward, successfully taking a system to flight, with the concomitant rigor and thoroughness, is a formidable task. The ASRG system had completed most of its flight system development. The proposed testing of a system at such an advanced level of development presents a singular opportunity for the advancement of future NASA power systems.

Also, since it may be years before a Stirling-based power system is flown, there is an opportunity to gather longlife performance data on flight-caliber Stirling convertors. The lack of long-life convertor data was one of the concerns with ASRG, and this concern could be at least partially addressed by starting tests now on ASRG hardware.

Knowledge gained from testing of ASRG hardware could be readily applied to the advancement of Stirling power systems in a variety of ways and to varying degrees. Recognizing this opportunity and the potential direction of Stirling power system development, three objectives have been identified for testing of ASRG hardware in support of Stirling technology advancement.

A first objective of the proposed testing is to demonstrate steady-state and dynamic performance of an integrated Stirling system converting heat to conditioned spacecraft bus power. This includes benchmarking convertor, controller, and generator system performance while simulating flight-like conditions under typical mission operation scenarios, including beginning of mission, end of mission, and diurnal Martian environmental testing. Tests will quantify efficiency, power, power quality, short-term and long-term convertor and controller stability, temperature sensitivity of the convertor, and DC bus voltage sensitivity of the controller. ${ }^{2}$ Data from these tests will be used to validate various system, subsystem, and component models that have been developed. No data exists yet for a flightlike integrated ASRG converting heat to conditioned spacecraft bus power, and the hardware from the ASRG flight development project presents an opportunity to fill that void.

A second objective of the proposed testing is to validate convertor, controller, convertor-controller interface, controller-spacecraft bus interface, and system level requirements. This activity will inform future Stirling power system requirement development and requirements flowdown and improve requirements definition, especially with the complex interfaces in Stirling power systems. Both internal interfaces and interfaces to the spacecraft are considered. ASRG system and subsystem requirements should be a good reference point for developing requirements for any future Stirling-based power system. Validating some of the more critical interfaces and requirements improves their value to future requirements development efforts.

As an example, one of the more complex interfaces is the electrical interface between the convertor and controller. This interface has bidirectional energy flow, and the peak voltage and current can be more than double nominal levels during extreme dynamic events such as launch vibration. Controller and convertor requirements need to capture not just the requirements during steady-state nominal operation, but also requirements for any condition within the allowable operating envelope (i.e., corner cases) or different combinations of events.

The third objective of the proposed testing is to continue extended operation of highest-pedigree ASCs to establish a database of component and convertor performance and reliability. Having high hours of reliable operation for Stirling convertors fills an important gap in the data. This data can be used to validate component models which can be the basis for models of future Stirling-based power system components. Demonstrated longlife extended operation builds confidence that any major failure modes have been identified and addressed.

\section{Available Hardware}

While much testing of Stirling convertors has been conducted over the past decade, limited system level testing has been done. To date, the highest fidelity generator system testing was conducted with the ASRG Engineering Unit (EU). After completing a series of system-level tests to qualification level thermal and dynamic environments 
at Lockheed Martin, the ASRG EU ran for over 33,000 hours at NASA GRC. This included 15,378 hours of operation with a first-generation controller called the EDU 1. The ASRG EU was taken off of test in 2013 for disassembly and inspection.

To take the ASRG to flight, many changes were made to the convertor and controller designs since the ASRG EU was built in 2007. It will be important to any future Stirling-based flight project to be able to leverage flight-like pedigree system-level test heritage. To that end, a high-fidelity engineering unit, the ASRG EU2, is being assembled at NASA GRC (Fig. 2). The ASRG EU2 will consist of the first pair of ASC-E3 convertors, Lockheed Martin's EDU 4 controller (a fourth generation controller), and an aluminum flight-like housing. ${ }^{3}$ Table I summarizes the most important differences between the ASRG EU, the ASRG EU2, and the ASRG QU as designed, to show how the EU2 is significantly different from the EU and much closer to the QU.

Table I. Comparison of ASRG system hardware (continued on next page).

\begin{tabular}{|c|c|c|c|c|}
\hline Detail & ASRG EU & ASRG EU2 & $\begin{array}{l}\text { ASRG QU design, } \\
\text { electrically heated }\end{array}$ & Comment \\
\hline Status & Built in 2007 and tested & Completing assembly & $\begin{array}{l}\text { Designed, components } \\
\text { built, but not assembled }\end{array}$ & \\
\hline Convertors & ASC-E \#2 and \#3 & ASC-E3 \#1 and \#2 & ASC-F \#1 and \#2 & $\begin{array}{l}\text { ASC-E3 and -F convertors } \\
\text { are built to the same } \\
\text { drawings and specifications } \\
\text { and same/similar processes }\end{array}$ \\
\hline $\begin{array}{l}\text { Convertor } \\
\text { design }\end{array}$ & $\begin{array}{l}\text { - Inconel } 718 \text { heater head } \\
\text { - } 650{ }^{\circ} \mathrm{C} \text { max hot-end } \\
\text { temp } \\
\text { - high-current low- } \\
\text { voltage alternator } \\
\text { - internal piston position } \\
\text { sensor }\end{array}$ & $\begin{array}{l}\text { - 247LC heater head } \\
\text { - } 840{ }^{\circ} \mathrm{C} \text { max hot-end } \\
\text { temp } \\
\text { - lower-current higher- } \\
\text { voltage alternator } \\
\text { - external piston } \\
\text { position sensor } \\
\text { - numerous design } \\
\text { details changed from } \\
\text { ASC-E } \\
\text { - numerous process } \\
\text { changes from ASC-E }\end{array}$ & $\begin{array}{l}\text { - Same as ASC-E3 \#1 } \\
\text { and \#2, but assembled in } \\
\text { clean room }\end{array}$ & \\
\hline $\begin{array}{l}\text { Electric } \\
\text { heat source }\end{array}$ & $\begin{array}{l}\text { Tested at Lockheed } \\
\text { Martin with GPHS-like } \\
\text { heat source; tested at } \\
\text { GRC with round nickel } \\
\text { block heat source }\end{array}$ & $\begin{array}{l}\text { Molybdenum heat } \\
\text { source with same } \\
\text { thermal mass and } \\
\text { external dimensions as } \\
\text { GPHS }\end{array}$ & $\begin{array}{l}\text { GPHS-like electric heat } \\
\text { source }\end{array}$ & \\
\hline $\begin{array}{l}\text { Thermal } \\
\text { insulation }\end{array}$ & Early design & $\begin{array}{l}\text { Improved design; uses } \\
\text { insulation intended for } \\
\text { QU }\end{array}$ & Same as EU2 & \\
\hline $\begin{array}{l}\text { Generator } \\
\text { housing } \\
\text { material }\end{array}$ & Beryllium & $\begin{array}{l}\text { Aluminum, with most } \\
\text { QU design changes plus } \\
\text { some simplifications to } \\
\text { reduce cost }\end{array}$ & $\begin{array}{l}\text { Beryllium, with design } \\
\text { changes from EU }\end{array}$ & $\begin{array}{l}\text { EU2 aluminum housing is } \\
\text { thermally equivalent to QU } \\
\text { housing. Thicknesses } \\
\text { adjusted to compensate for } \\
\text { thermal conductivity } \\
\text { differences. }\end{array}$ \\
\hline Fins & 2.5” long beryllium fins & 5” long aluminum fins & 5” long beryllium fins & $\begin{array}{l}\text { EU2 aluminum fins are } \\
\text { thermally equivalent to QU } \\
\text { fins }\end{array}$ \\
\hline $\begin{array}{l}\text { Electrical } \\
\text { shunts }\end{array}$ & $\begin{array}{l}\text { Resistors internal to the } \\
\text { housing }\end{array}$ & $\begin{array}{l}\text { Resistor bank in the test } \\
\text { rack }\end{array}$ & $\begin{array}{l}\text { Shunt Dissipation Unit } \\
\text { (SDU) mounted on } \\
\text { outboard end of GHA }\end{array}$ & $\begin{array}{l}\text { QU-like SDU could be } \\
\text { mounted on end of the EU2 } \\
\text { GHA if desired }\end{array}$ \\
\hline Controller & EDU $1 \mathrm{ACU}^{4}$ & $\begin{array}{l}\text { EDU } 4.0 \text { or EDU } 4.1 \\
\text { ACU }\end{array}$ & QU ACU & $\begin{array}{l}\text { The EDU } 4.0 \text { and } 4.1 \text { are } \\
\text { functional equivalent } \\
\text { predecessors to the QU ACU }\end{array}$ \\
\hline
\end{tabular}




\begin{tabular}{|c|c|c|c|c|}
\hline Detail & ASRG EU & ASRG EU2 & $\begin{array}{l}\text { ASRG QU design, } \\
\text { electrically heated }\end{array}$ & Comment \\
\hline $\begin{array}{l}\text { Controller } \\
\text { design }\end{array}$ & $\begin{array}{l}\text { - N+1 redundant system } \\
\text { architecture } \\
\text { - Sunpower control } \\
\text { algorithm utilizing an H- } \\
\text { bridge circuit }^{5} \\
\text { - H-bridge performs AC } \\
\text { to DC boost operation } \\
\text { and maintains output DC } \\
\text { bus voltage } \\
\text { - multiple control loops } \\
\text { - many features and } \\
\text { design details required } \\
\text { for flight not } \\
\text { implemented }\end{array}$ & $\begin{array}{l}\text { - Same circuits and } \\
\text { board layout as QU } \\
\text { - flight equivalent parts } \\
\text { - boards not conformal } \\
\text { coated } \\
\text { - no mechanical staking } \\
\text { - engineering level } \\
\text { quality processing } \\
\text { - modified housing } \\
\text { from QU design } \\
\text { - a few features required } \\
\text { for flight not } \\
\text { implemented } \\
\text { - EDU } 4.0 \text { has white } \\
\text { wires; EDU } 4.1 \text { replaces } \\
\text { most white wires with } \\
\text { board traces }\end{array}$ & $\begin{array}{l}\text { - N+1 redundant system } \\
\text { architecture } \\
\text { - Sunpower control } \\
\text { algorithm utilizing an H- } \\
\text { bridge circuit } \\
\text { - H-bridge only performs } \\
\text { AC to DC boost } \\
\text { operation } \\
\text { - added DC output stage } \\
\text { - eliminated EDU 1’s } \\
\text { multiple control loops } \\
\text { - significant circuit } \\
\text { redesign and component } \\
\text { changes from EDU } 1\end{array}$ & $\begin{array}{l}\text { EDU } 4.0 \text { and } 4.1 \text { will } \\
\text { perform electrically like the } \\
\text { QU ACU but cannot be } \\
\text { environmentally tested or } \\
\text { operated in vacuum }\end{array}$ \\
\hline $\begin{array}{l}\text { Controller } \\
\text { location }\end{array}$ & Attached to the GHA & Remotely mounted & Remotely mounted & \\
\hline GHA paint & Z-93 & $\begin{array}{l}\text { Dupont Imron on } \\
\text { housing; Sherwin } \\
\text { Williams Polane on fins }\end{array}$ & Z-93 & $\begin{array}{l}\text { EU2 paints have similar } \\
\text { emissivity to Z-93, but } \\
\text { different absorptivity. EU2 } \\
\text { paints are more durable } \\
\text { during handling }\end{array}$ \\
\hline $\begin{array}{l}\text { Assembly } \\
\text { processes } \\
\text { and quality }\end{array}$ & Engineering level by LM & $\begin{array}{l}\text { Engineering level, by } \\
\text { GRC with LM support }\end{array}$ & Flight level by LM & $\begin{array}{l}\text { LM support of EU2 assembly } \\
\text { results in EU lessons learned } \\
\text { and other knowledge to be } \\
\text { applied to EU2 }\end{array}$ \\
\hline
\end{tabular}

Given that the ASRG flight development project had completed fabrication of many of the components for the ASRG QU, one might ask, Why not complete the QU instead of the EU2? There are a number of reasons. An ASRG flight demonstration mission is being considered, so there is a desire to preserve the QU hardware for that possibility. The EU2 housing is aluminum, not beryllium, which has some advantages from a safety and handling standpoint. Also, the aluminum housing was designed to handle an internal vacuum, which allows simulation of space-like environment behavior of the insulation and convertors without the complexity and limitations of putting the entire GHA in a thermal vacuum chamber. The EU2 has some design simplifications, which reduces the time required to assemble and test. For example, the EU2 heat source and heat source preload assembly is less complex than the QU's. Also, when hardware from the ASRG flight development became available after the project was terminated, a number of EU2 components were changed out and replaced with hardware that had been intended for the QU or flight. This includes the insulation and some of the instrumentation.

This proposed test program does not intend to

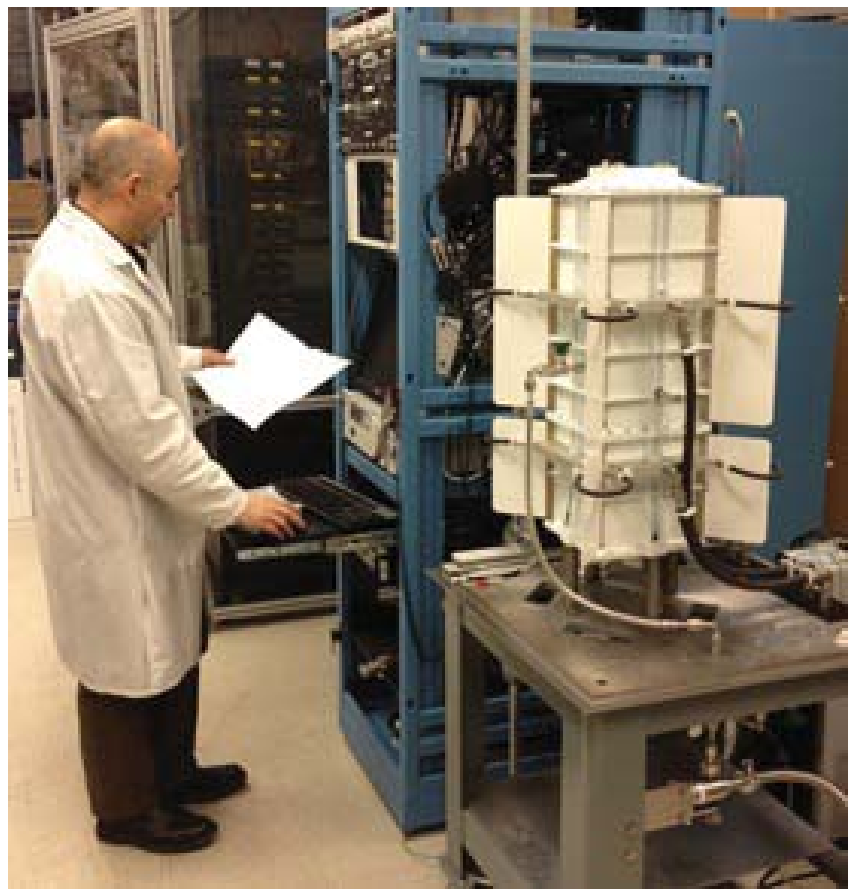

Figure 2. The ASRG EU2 Generator Housing Assembly being set up for test in the Stirling Research Laboratory. 
test the ASRG EU2 to the full suite of qualification tests. Qualification tests are mission specific, and the EU2 was not designed to be able to undergo all qualification tests, such as random vibration, shock, and sine transient.

As a related point, it should be noted that while the ASRG documentation defines the system requirements for a fueled ASRG, the ASRG EU2 was not designed or built to meet those requirements. Thus the ASRG EU2 tests will not "verify" compliance with ASRG requirements in a strict sense of the word. Rather, the tests will provide an indication of the ability of the ASRG design to meet certain requirements or quantify ASRG EU2 performance relative to certain requirements.

\section{ASRG EU2 Test Configurations}

The EU2 and its test facility are designed to support a variety of test configurations, enabling a wide variety of tests to be conducted, some of which have already been identified, and some which may be identified as future objectives are identified to support continued Stirling technology development. As with the ASRG EU, the EU2 can be operated under AC bus control or ACU control. While the EU was operated with the two convertors on a common AC bus, the EU2 test rack will be set up with two independent AC buses which are synchronized. This configuration mimics the architecture of the ACU and permits the two convertors' piston amplitudes to be set independently.

The GHA is designed to accommodate a wide range of ground and mission environments, making it easier to conduct tests while simulating the different thermal characteristics of these environments. The GHA can be filled with argon as would be the case during ground operations. The GHA can be evacuated to mimic the vacuum of space so that the insulation and convertors behave thermally as they would in space. Finally, the GHA can be backfilled with a Martian-like atmosphere to create internally the thermal characteristics found during operation on the Martian surface.

\section{Test Details}

In order to gain knowledge from testing of ASRG hardware that could be readily applied to the advancement of Stirling technology, a number of tests have been developed. These tests are to support the test objectives mentioned above. Table II summarizes many of the tests planned for the ASRG hardware. It maps the planned tests to the three test objectives and clarifies which hardware will be used for each test.

\section{A. Performance and Characterization Tests}

Over the years of ASRG development, the project team created a series of tests that can be used to characterize the steady-state and dynamic behavior of the ASRG. The ASRG EU2 will be put through this series of tests in a rigorous and controlled fashion to provide extensive data for future system development. These tests were conducted on the ASRG EU, and many of them are documented in Ref. 2. The EU2 tests will be conducted with the GHA filled with argon and with an internal vacuum, to characterize operation both on the ground and in space. While the specific performance of a future Stirling power system may be different than the ASRGs, validating ASRG system level models provides a measure of confidence in the methods used to predict generator steady-state and dynamic behavior using subsystem data. It also provides a data-based benchmark for comparison.

1. ASRG EU2 steady-state performance mapping

The ASRG EU2 steady-state performance will be measured at beginning of mission and end of mission operating points over a range of rejection temperatures. The EU2 will be instrumented with power meters that measure heater power input, AC power out of the convertors and into the ACU, and DC power out of the ACU. So besides measuring overall generator performance, the ASC and ACU performance will also be quantified to measure efficiencies and losses at the subsystem level when operating as an integrated system. The data from ASC performance can be compared to data taken during ASC performance mapping ${ }^{6}$ to evaluate the accuracy of methods used to measure convertor performance in air that rely on thermal analysis. ${ }^{7}$ The data from ACU performance can be compared to performance measured during ACU development. ${ }^{1}$

2. ASC setpoint voltage/AC bus voltage variation test

The primary control input to the ASRG is ASC setpoint voltage. The ASC setpoint voltage is an input to the active power factor control algorithm in the ACU, which then sets the AC voltage to the alternator. The alternator AC voltage, in conjunction with convertor operating temperatures, determines the piston amplitude. Increasing the ASC setpoint voltage has the effect of increasing piston amplitude, although the transfer function contains complex transient dynamics at the system level, and the magnitude of the piston amplitude change resulting from an ASC setpoint voltage change is dependent on generator operating point. When operating under AC bus control, the analog to ACU's ASC setpoint voltage is the AC bus voltage. 
Table II. Summary of tests planned for ASRG hardware.

\begin{tabular}{|c|c|c|c|c|}
\hline \multirow[b]{2}{*}{ 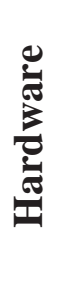 } & \multirow[b]{2}{*}{ Test } & \multicolumn{3}{|c|}{ Test objectives } \\
\hline & & $\begin{array}{l}\text { 1. Demonstrate } \\
\text { integrated } \\
\text { system } \\
\text { performance; } \\
\text { validate models }\end{array}$ & $\begin{array}{l}\text { 2. Validate } \\
\text { requirements: } \\
\text { system, } \\
\text { subsystem, } \\
\text { and interfaces }\end{array}$ & $\begin{array}{l}\text { 3. Validate } \\
\text { ASC reliability } \\
\text { model and } \\
\text { demonstrate } \\
\text { long life } \\
\text { operation }\end{array}$ \\
\hline \multirow{11}{*}{ 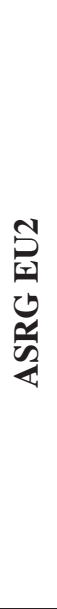 } & ASRG EU2 steady-state performance mapping & $\mathrm{X}$ & $\mathrm{X}$ & \\
\hline & ASC setpoint voltage/AC bus voltage variation test & $\mathrm{X}$ & $\mathrm{X}$ & \\
\hline & Heat input variation test & $\mathrm{X}$ & $\mathrm{X}$ & \\
\hline & Hot-end temperature vs. efficiency test & $\mathrm{X}$ & $\mathrm{X}$ & \\
\hline & Effect of rejection temperature on performance test & $\mathrm{X}$ & $\mathrm{X}$ & \\
\hline & Disturbance force characterization test & $\mathrm{X}$ & $\mathrm{X}$ & \\
\hline & One convertor out test & $\mathrm{X}$ & $\mathrm{X}$ & \\
\hline & Martian diurnal test & $\mathrm{X}$ & $\mathrm{X}$ & \\
\hline & various interface tests & $\mathrm{X}$ & $\mathrm{X}$ & \\
\hline & $\begin{array}{l}\text { ASRG EU2 power quality tests in Radioisotope Power } \\
\text { Systems, System Integration Laboratory (RSIL) }\end{array}$ & $\mathrm{X}$ & $\mathrm{X}$ & \\
\hline & ASRG EU2 extended operation & $\mathrm{X}$ & & $\mathrm{X}$ \\
\hline \multirow{4}{*}{ 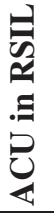 } & Power quality tests & & $\mathrm{X}$ & \\
\hline & Multiple ASRGs on a single spacecraft bus & & $\mathrm{X}$ & \\
\hline & Fault propagation tests & & $\mathrm{X}$ & \\
\hline & ACU model validation & $\mathrm{X}$ & $\mathrm{X}$ & \\
\hline \multirow[t]{3}{*}{$\sum_{0}^{\infty}$} & $\begin{array}{l}\text { Screening and characterization tests: } \\
\text {-Piston centering } \\
\text {-Natural frequency } \\
\text {-ASC performance mapping } \\
\text {-Horizontal operation } \\
\text {-Run-in operation } \\
\text {-Flight acceptance vibration }\end{array}$ & $\mathrm{X}$ & $\mathrm{X}$ & $\mathrm{X}$ \\
\hline & Extended operation & & & $\mathrm{X}$ \\
\hline & Periodic characterization tests during extended op. & $\mathrm{X}$ & & $\mathrm{X}$ \\
\hline
\end{tabular}

The ASC setpoint voltage/AC bus voltage variation test quantifies the transient and steady-state effects of step changes in ASC setpoint voltage or AC bus voltage. The data will be compared to calculated hot-end temperature and piston amplitude sensitivities to voltage variation on the ASRG EU2, providing guidance for predicting such sensitivities for future Stirling systems.

3. Heat input variation test

Radioisotope power systems which are fueled by Pu-238 see a $0.79 \%$ decrease in heat input every year due to the fuel decay. The heat input variation test simulates this decay and the effect on the generator. Decreasing the heat input results in a decrease in hot-end temperature. The planned approach to operating the generator as heat input decreases involves decreasing the piston amplitude in order to increase hot-end temperature, thereby improve conversion efficiency and increase output power. This test mimics the fuel decay and the adjustment in piston amplitude in response to increase hot-end temperature.

4. Hot-end temperature vs. efficiency test

The purpose of this test is to quantify the effect of hot-end temperature on generator efficiency at different operating points. There is a tradeoff between higher convertor efficiency at higher hot-end temperatures and higher insulation losses. With a higher hot-end temperature the Stirling convertor by itself is generally more efficient. But at the same time, higher hot-end temperatures result in greater insulation losses. This test shows how these two 
effects trade off and helps characterize the optimal range of operation. Analysis has predicted a fairly flat efficiency curve in vacuum over a broad hot-end temperature range. This test will confirm the analysis.

5. Effect of rejection temperature on performance test

During a mission a generator may experience a change in rejection temperature over a short period of time, for example, during a Venus gravity assist maneuver or due to a change in shading while in a high solar flux environment. The effect of rejection temperature on performance test will quantify how generator parameters change in response to just a change in the heat rejection environment.

\section{B. Special System Tests}

The ASRG EU2 presents an opportunity to conduct system-level tests that have been of special interest to missions.

1. Disturbance force characterization test

Stirling power systems are dynamic power systems with moving parts that generate disturbance forces. Missions need to take these forces into account when designing spacecraft and mounting structures. The ASRG incorporates two convertors in an opposed configuration so that the disturbance force from one convertor is largely cancelled by the other. The ACU has an input, the relative phase of the voltage waveforms, which is one control parameter the mission can use to better cancel the disturbance force from each convertor. Another control parameter is to vary the relative piston amplitudes of the two convertors. The disturbance force characterization test will quantify the effects of these two approaches to minimizing disturbance force and validate the disturbance force dynamic model of the generator.

\section{One convertor out test}

The ASRG is able to continue to operate with one convertor out (not producing power), although at a reduced output power level. In this case the net disturbance force from the generator is higher, since the disturbance force from the operating convertor is no longer cancelled by the other convertor. In addition, there is a small secondary effect on the operating convertor due to the different thermal environment and the small increased oscillation of the convertor casing. The thermal change is due to the decreased thermal rejection from the non-operating convertor's cold end and the increased heat flux at the non-operating convertor's hot end. The increased casing oscillation is expected to result in a slight decrease in piston and displacer amplitudes, affecting hot-end temperature, and to a lesser extent, output power. The one convertor out test will simulate one convertor out by stalling one convertor while the other continues to operate. Data from this test will be used to further validate the disturbance force dynamic model of the generator, but now using a significantly higher input force. The secondary thermal and mechanical effects will be quantified to the extent possible. It may be difficult to perfectly mimic the thermal effects of one convertor out without modifying internal generator hardware or testing in a thermal vacuum environment. The test will be conducted with different GHA mounting stiffnesses ranging from a rigid mount to a nearly floating mount. The mounting stiffness affects the magnitude of casing oscillation, with higher oscillation occurring with the floating mount.

3. Martian diurnal test

The Martian day-night cycle would impart a cyclic variation on the ASRG rejection temperature. This in turn would affect the convertor operating point, piston amplitude, and hot-end temperature. Demonstrating the effects of the Martian diurnal cycle on the ASRG would demonstrate to mission planners and developers of future Stirling power systems on how these effects can affect such a power system.

\section{Interface Testing}

The interface between the controller and the convertor is complex, containing bidirectional energy flows influenced by many factors. Completely capturing and quantifying the interface requirements when considering all aspects of a space mission, including startup, fueling, test, integration, launch, and so forth, is challenging. This part of the test program will include tests to better understand interfaces for future power systems. Figure 3 shows the major interfaces in the ASRG.

The tests already described would provide data related to mechanical, thermal, and electrical interfaces both within the generator and between the generator, the spacecraft, and the generator's environment. Additional tests may be conducted to study specific aspects of certain interfaces. For example, a test may be conducted to quantify core losses between the alternator and controller associated with the high frequency switching of the H-bridge circuit. 


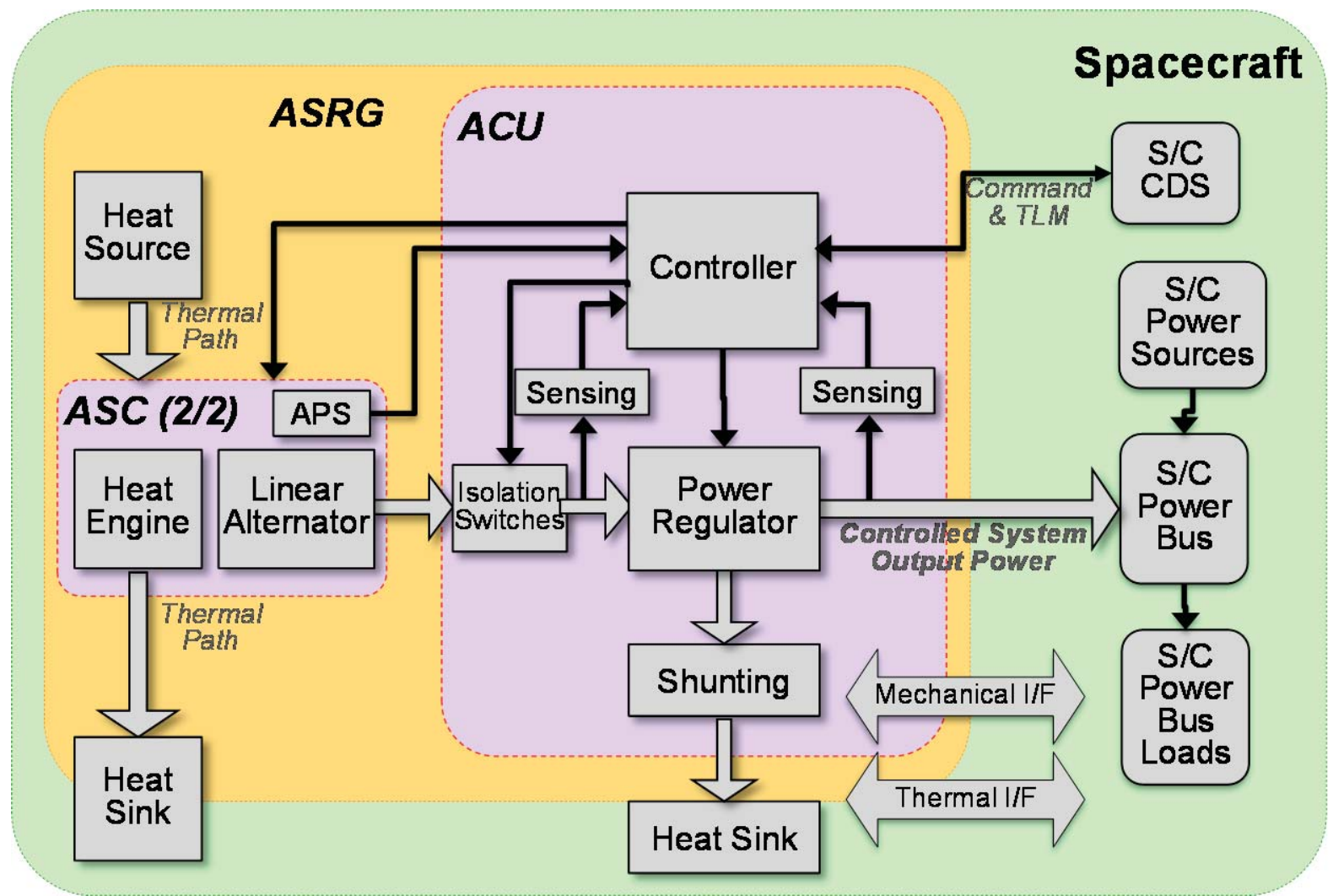

Figure 3. ASRG interfaces. APS = ASC Position Sensor; $/ \mathrm{C}=$ spacecraft.

\section{Controller Testing}

Controller-only tests will focus on the electrical interface to the spacecraft. Tests will be conducted in NASA GRC's Radioisotope Power Systems, System Integration Laboratory (RSIL). These tests will be conducted with active electronic convertor simulators in place of actual convertors to allow for ease of testing and to permit a wider range of inputs.

The first series of proposed tests will assess power quality and other controller metrics. These tests will focus on measuring the power quality from the ACU, validation of the fault protection within the ACU, and testing of multiple ACUs on a spacecraft power bus, simulating multiple ASRGs. The power quality tests will measure the voltage ripple and stability through a variety of test conditions with both a battery bus and capacitive bus. Spacecraft load simulators will be varied to see the extent this variation has on the output power quality. Fault protection validation will validate the protection within the ACU. One key test here is to vary the power bus to simulate the expected power variations from events such as firing pyros or faults within the spacecraft. This testing would ensure that these faults or events are contained within the spacecraft and do not cause the ACU to switch to its spare card prematurely. When multiple ACUs are available, testing will be done to characterize the power quality of the system, and to ensure that spacecraft or ACU faults do not propagate across fault containment regions.

Many mission configurations need to integrate multiple radioisotope generators to power the spacecraft when a single generator cannot provide sufficient power. The two proposed Discovery 12 missions that used ASRG, TiME and CHopper, were both designed around two ASRGs. While the ASRG did not have an explicit 'multiple generators on a single bus' requirement, it was expected that the design of the ASRG electrical interface didn't preclude having multiple generators on a single bus. NASA GRC is procuring two controllers from Lockheed Martin, EDU 4.0 and EDU 4.1, and will test these two controllers on a single bus to demonstrate this capability. This test will quantify the effect on power quality, and will look for effects on voltage ripple perhaps related to the fact that the controller's clocks are not synchronized. It will also look for interactions among controllers as the DC bus voltage moves into and out of over voltage and under voltage conditions. 


\section{E. Extended Operation Testing}

After completion of performance, demonstration, and characterization testing, the ASRG EU2 will continue on extended operation. Besides generating long-life data, this testing will provide an opportunity to quantify any performance degradation. Some potential minor degradation modes have been hypothesized, but for the most part have not been quantified empirically. Convertor and generator performance will be accurately measured periodically at certain operating points to monitor for any changes in performance and validate degradation models. Operating conditions during this phase will mimic expected flight conditions to the extent possible, including thermal environment variation and vacuum, with the goal of demonstrating long life in a "test as you fly" configuration.

Convertor testing that had been planned under the ASRG project largely continues under Stirling technology advancement. Because demonstrating high reliability is so critical to any space power system, and this invariably necessitates years of testing, this work will continue. Multiple high pedigree convertors will be put on test under a flight-like test profile, with the goal of accumulating a significant number of failure-free years of operation (Fig. 4). Extended operation data will be used to validate the ASC reliability model. The convertors will be monitored for small fluctuations in power as a method to monitor for contact of internal moving parts. Extended operation with

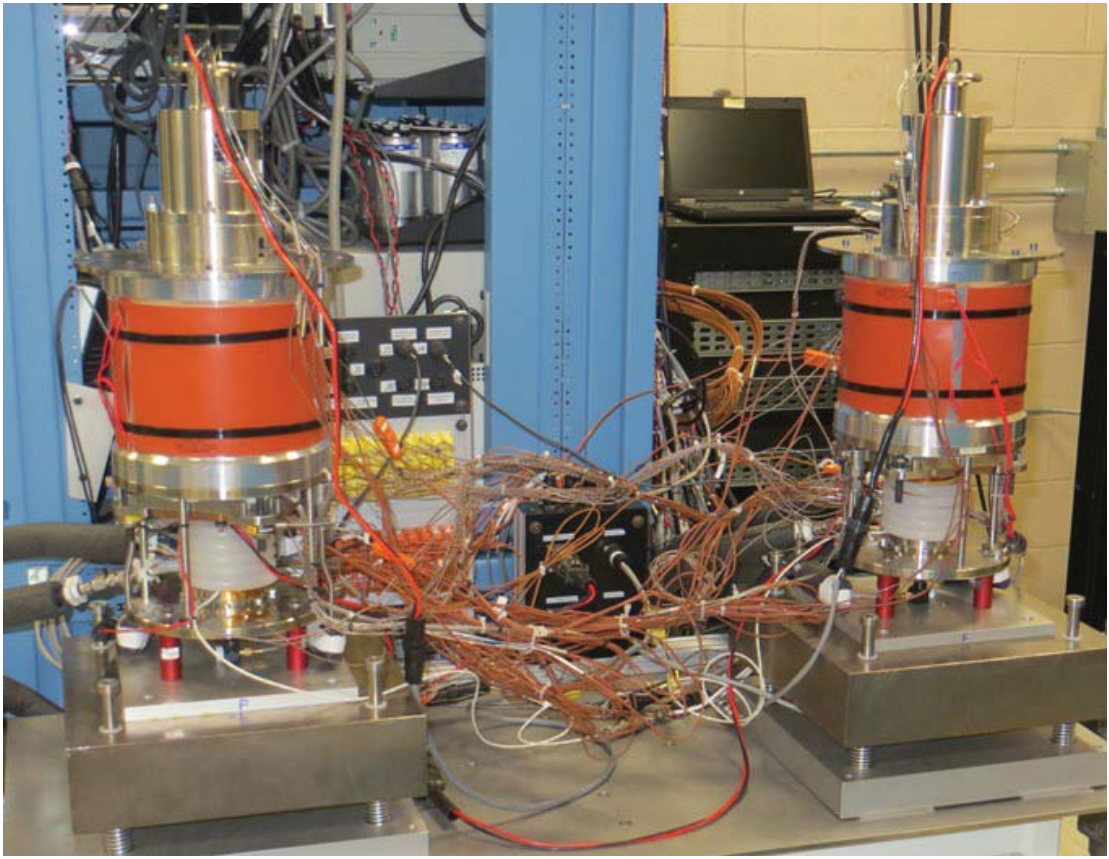

Figure 4. ASC-E3 \#3 and \#4 under test in NASA GRC's Stirling Research Laboratory.

no significant fluctuations in power provides evidence of non-contact operation.

One of the biggest challenges with developing Stirling-based power systems for flight has been overcoming the hurdle of establishing sufficient confidence in the long term reliability of a dynamic power system without long term system level life data. Traditional reliability methods rely on testing a sufficiently large number of the systems for three or four times the life to establish a statistically significant result for system reliability. It is not possible to accelerate life testing of Stirling-based systems, so to demonstrate, for example, 17-year life, would require multiple systems operating for 51 to 68 years by traditional reliability methods. This is clearly not realistic. So other methods are employed to establish long term reliability. ${ }^{8}$

1. System life phases

From the reliability standpoint, Figure 5 shows the typical three phases of a system life with associated hazard rate. Each phase is associated with specific failure modes and mitigation.

Early-life phase has most of its risks associated with fabrication defects. Stringent quality assurance and adequate burn-in tests provide the mitigation for these infant mortality risks. We will also be relying on extensive production screening tests to screen for defects during this phase of our testing early in our test flow.

Mid-life phase extends the majority of the system design life. We are assuming that this area is dominated by random failure risks with a near-constant hazard rate. In other words, high stress conditions and potential failures could occur randomly. The risk mitigations of this phase consist of extensive component tests, redundancy features, and system life tests. For this phase, failures are considered to be independent of time and modeled with the exponential model. Typically, an equivalent life test using cumulative test duration with multiple units is acceptable.

Assumptions underlying the ability to accumulate hours from multiple units for the useful life part of the curve include:

1. Random failure modes are assumed over the operational life time of multiple units

2. Failure modes are assumed to be independent 
3. Failure rates are assumed to be constant, with exponential function model assumed

Late-life phase is dominated with risks associated with wear-out or degradation. Accelerated tests, or complete life test (if achievable), would ensure the design will not experience these risks prematurely.

The application of this system life phase model to the ASC-E3 test program needs to be done judiciously. This means that we need to address some key questions associated with this model. The first is to adequately address infant mortality issues. This is done by ensuring that adequate production screening tests are in place. Based on previous experience and an evaluation of the screening tests, the test program will define the formal change of phase, from Early-Life to Mid-Life, thus ending the infant mortality phase.

During the mid-life phase of testing it is essential that the ASC design is stable with respect to time. This means proving that the design is not wearing during nominal operations and that any known degradation modes are behaving as predicted.

Another aspect of applying this model to the test program is through the success criteria. Criteria for failure will need to evolve with the unit and point in test profile. These criteria will be used to determine the following:

1. What counts as a statistical failure?

2. When do we shut down the test or keep the test running?

3. What does it take to validate a degradation model?

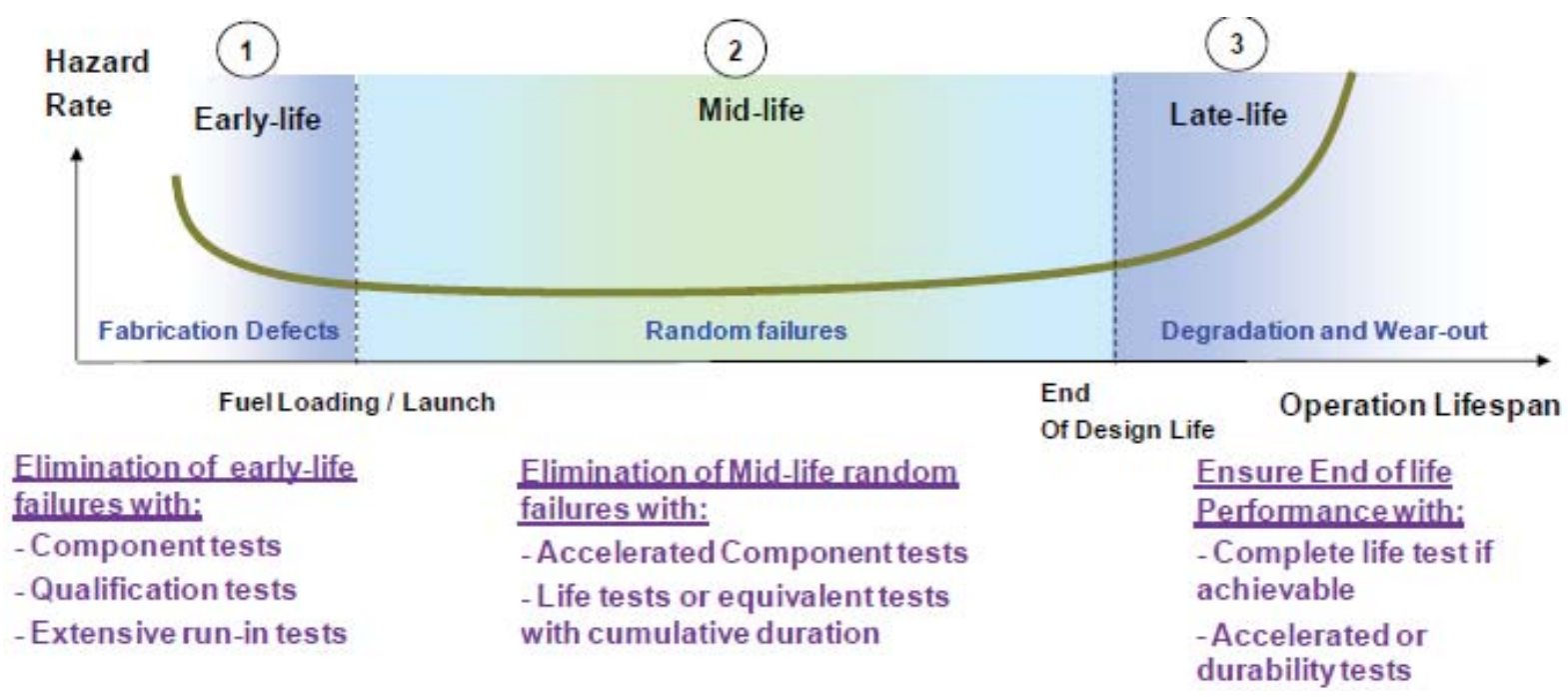

Figure 5. System life phases.

\section{2. $\quad$ Screening Tests}

Screening and characterization tests assess convertors for fabrication defects and provide baseline data used to monitor the convertors for changes in performance over life. The sequence of ASC production screening and characterization tests is shown in Fig. 6. The piston centering test characterizes how the piston moves when a DC current is applied to the alternator.

The natural frequency test empirically determines the convertor natural frequency. Since the convertor natural frequency is a function of numerous parameters within the convertor, by periodically conducting this test during extended operation, a change in any one of many parameters can be detected this way (although not necessarily uniquely identified).

The performance map test confirms convertor performance is within spec and characterizes performance at the beginning of life for each convertor. The performance map test is run periodically during extended operation to monitor the convertor for changes in performance.

The horizontal operation test checks gas bearing performance under 1-g loading of the piston and displacer rod bearings.

The flight acceptance vibration test exposes each convertor to the vibration it would see during flight acceptance testing and launch, in keeping with the "test as you fly" philosophy. This is performed sometime after the 2,000 hours of run-in operation.

Failures during this infant mortality period do not count against the reliability statistics due to probable cause being a manufacturing defect. Convertors that pass the 2,000-hour mark with no failures become part of the extended life pool, with the hours of operation to that point included in the total accumulated hours of operation. 


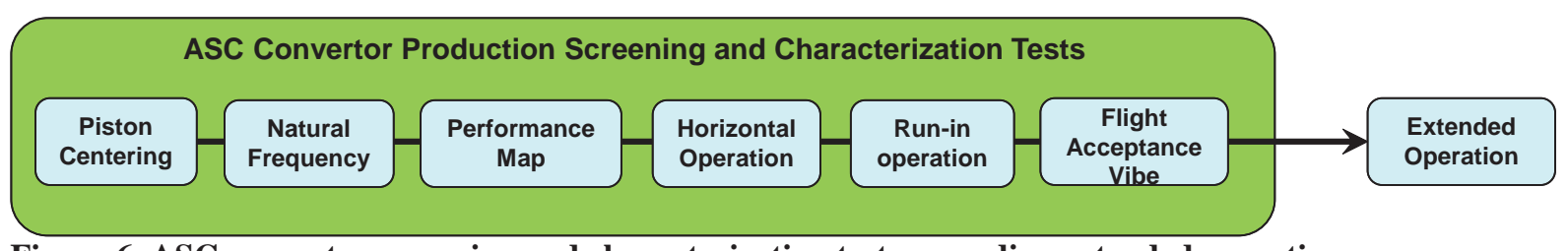

Figure 6. ASC convertor screening and characterization tests preceding extended operation.

\section{Validate Reliability Model}

The ASC reliability model will be validated through the accumulation of failure-free hours of extended operation. This cumulative test time, although limited in sample size, can provide additional confidence that important randomly occurring failure mechanisms have been controlled. The proposed plan is to document the results from this additional testing to assure that failure mechanisms have been controlled effectively by the corrective actions implemented previously during ASC development.

Figure 7 shows cumulative extended operational test time as a function of mission time and confidence level where Mean-Time-To-Failure (MTTF) is equated with Mission Time. The chart can be used as a tool to gauge how much accumulated testing is needed for a particular mission duration and desired confidence level. These confidence levels were calculated assuming an exponential distribution. The goal for extended life testing is to accumulate as many hours as possible with existing ASC-E3 hardware, ASC-E3 convertors being built, and the integrated EU2 hardware.

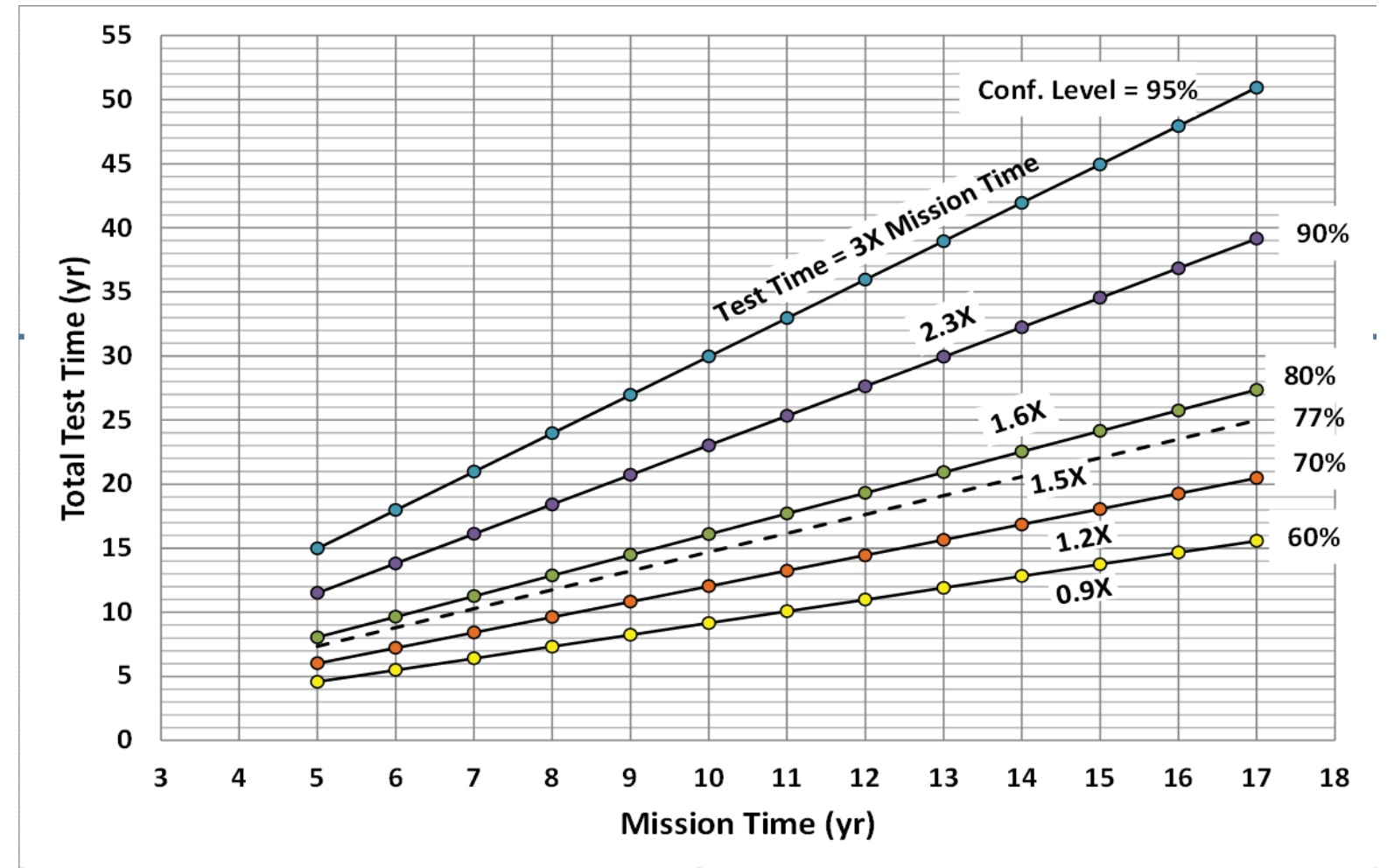

Figure 7. Total test time without failures for MTTF $=$ mission time.

\section{Conclusion}

The Stirling radioisotope generator hardware test program at NASA GRC plays a vital role in the development of Stirling-based power systems. Under the ASRG project, significant progress was made towards the development of a flight-qualified radioisotope power system. The proposed test program described here will provide data on the performance and reliability of the ASRG hardware, at the system, sub-system, and component level, in support of 
future Stirling-based power system development. If funded, it will provide needed data on performance at the generator level, extended operation, ACU characterization and validation of all the interfaces.

\section{Acknowledgments}

The authors wish to acknowledge all of the members of the ASRG Integrated Federal Project team who designed, analyzed, and procured the hardware being put under test at NASA GRC. This work was funded with the support of the NASA Science Mission Directorate and the Radioisotope Power Systems Program Office. The research described in this paper was carried out at the National Aeronautics and Space Administration (NASA), and the Jet Propulsion Laboratory, California Institute of Technology, under a contract with NASA. Any opinions, findings, conclusions, or recommendations expressed in this article are those of the authors and do not necessarily reflect the views of NASA.

\section{References}

${ }^{1}$ Chan, T., Wiser, J., Brown, G., Florin, D., and Oriti, S.M., "System-Level Testing of the Advanced Stirling Radioisotope Generator Engineering Hardware," Proceedings of the Twelfth International Energy Conversion Engineering Conference (IECEC 2014) AIAA, Cleveland, OH, 2014.

${ }^{2}$ Lewandowski, E. J. and Schreiber, J. G., "Testing to Characterize the Advanced Stirling Radioisotope Generator Engineering Unit,” Proceedings of the Eighth International Energy Conversion Engineering Conference (IECEC 2010) AIAA, Nashville, TN, 2010.

${ }^{3}$ Oriti, S. M., “Test Hardware Design for Flight-like Operation of Advanced Stirling Convertors (ASC-E3),” Proceedings of the Tenth International Energy Conversion Engineering Conference (IECEC 2012) AIAA, Atlanta, GA, 2012.

${ }^{4}$ Leland, D. K., Priest, J. F., Keiter, D. E., and Schreiber, J. G., "Development of a Power Electronics Controller for the Advanced Stirling Radioisotope Generator,” Proceedings of Fifth International Energy Conversion Engineering Conference (IECEC 2007), AIAA, St. Louis, Missouri, 2007.

${ }^{5}$ Holliday, E.S., "Controller Computing a Virtual Tuning Capacitor for Controlling a Free-Piston Stirling Engine Driving a Linear Alternator,” U.S. Patent 7,511,459, March 31, 2009.

${ }^{6}$ Oriti, S.M., "Performance Measurement of Advanced Stirling Convertors (ASC-E3)," Proceedings of the Eleventh International Energy Conversion Engineering Conference (IECEC 2013), AIAA, San Jose, CA, 2013.

${ }^{7}$ Wilson, S.D., et al., "Overview of Heat Addition and Efficiency Predictions for an Advanced Stirling Convertor," Proceedings of the Ninth International Energy Conversion Engineering Conference (IECEC 2011), AIAA, San Diego, CA, 2011.

${ }^{8}$ Marquardt, E.D., "Studying Reliability: Cryocoolers and Power Convertors," Space Technology and Applications International Forum - STAIF 2002, Albuquerque, NM, AIP Conference Proceedings, Vol. 608, pp. 945-951, 2002. 